\title{
Genetic variants associated with skin photosensitivity in a southern European population from Spain
}

\begin{tabular}{|r|l|}
\hline Journal: & Photodermatology, Photoimmunology \& Photomedicine \\
\hline Manuscript ID & PHOTO-OA-03-18-1011.R1 \\
\hline Manuscript Type: & Original Article \\
\hline Date Submitted by the Author: & n/a \\
\hline Complete List of Authors: & $\begin{array}{l}\text { Hernando, Barbara; Universitat Jaume I, Medicine } \\
\text { Sanz-Page, Elena; Universitat Jaume I, Medicine } \\
\text { Pitarch, Gerard; Hospital General de Castellon, Dermatology } \\
\text { Mahiques, Laura; Hospital General de Castellon, Dermatology } \\
\text { Valcuende-Cavero, Francisca; Hospital de La Plana, Dermatology } \\
\text { Martinez-Cadenas, Conrado; Universitat Jaume I, Medicine }\end{array}$ \\
\hline Keywords: & Photosensitivity, Pigmentation, Polymorphisms, UV Light \\
\hline & \multicolumn{2}{|l}{} \\
\hline
\end{tabular}


Title: Genetic variants associated with skin photosensitivity in a southern European population from Spain

\author{
Authors: Barbara Hernando ${ }^{\mathrm{a}}$, Elena Sanz-Page ${ }^{\mathrm{a}}$, Gerard Pitarch ${ }^{\mathrm{b}}$, Laura Mahiques ${ }^{\mathrm{b}}$, \\ Francisca Valcuende-Cavero ${ }^{\mathrm{c}}$, Conrado Martínez-Cadenas ${ }^{\mathrm{a} *}$ \\ ${ }^{\mathrm{a}}$ Department of Medicine, Jaume I University of Castellon, Ave. Sos Baynat. 12071, \\ Castellon, Spain \\ ${ }^{b}$ Department of Dermatology, Castellon University General Hospital. Ave. Benicassim, \\ 12004, Castellon, Spain. \\ ${ }^{\mathrm{c}}$ Department of Dermatology, La Plana University Hospital. Carretera Villarreal- \\ Burriana, 12540, Villarreal, Spain.
}

\title{
To whom correspondence should be addressed:
}

*Conrado Martinez-Cadenas. Department of Medicine, Jaume I University of Castellon, Ave. Sos Baynat. 12071, Castellon, Spain.

Telephone number: +34964387607

FAX: +34964387750

Email: ccadenas@uji.es

Manuscript word count: 2,351

Number of items (Figures and Tables): 5 


\section{CONFLICT OF INTERESTS}

The authors have no conflict of interest to declare. 


\begin{abstract}
Background/Purpose: Recent GWAS studies, mostly performed in populations of North European origin, have identified the genetic loci associated with pigmentation, sun sensitivity, freckling, and skin cancer susceptibility. Here we aimed at addressing the genetic determinants of sunlight sensitivity in Spain, a southern European population.
\end{abstract}

Methods: Nine SNPs located in 8 pigmentation-related genes (IRF4, TYR, ASP, HERC2, OCA2, BNC2, SLC24A4 and SLC45A2) were genotyped in 456 Spaniards. Additionally, the complete sequence of the $M C 1 R$ gene was obtained, testing each nonsynonymous mutation supported by the classification as $\mathrm{R}$ or $\mathrm{r}$ alleles. A standardised questionnaire was used to collect demographic characteristics, pigmentation and sun sensitivity traits, as well as sun exposure habits.

Results: MC1R R alleles and IRF4 rs12203592 were significantly associated with sunlight sensitivity at the Bonferroni-corrected level $\left(P\right.$-value $\left.<4.54 \times 10^{-3}\right)$. Genetic variants in SLC45A2 (rs16891982) and HERC2 (rs12913832) were also found to be significantly associated with skin photosensitivity in our Spanish sample. Interaction analysis using the MDR method revealed epistatic effects when these four variants were considered together.

Conclusion: $M C 1 R, I R F 4, H E R C 2$ and $S L C 45 A 2$ play a significant role in skin sensitivity to sunlight in the Spanish population. Moreover, interaction among these four loci seems to modulate the ability of the skin to respond to UV radiation.

Keywords: Photosensitivity, Pigmentation, Polymorphisms, UV Light 


\section{INTRODUCTION}

In recent years, there have been important advances in the elucidation of the genetic determinants of human skin colour, skin sensitivity to sunlight and tanning ability (1-8). Both cutaneous pigmentation and the skin's response to sunshine are extremely relevant to individual susceptibility to developing skin cancers (9-11).

Although skin sensitivity to ultraviolet (UV) radiation and the ability to tan are genetically determined, exposure to ambient sunlight is necessary for UV light to reveal its harmful effects on human skin (12). People with high sensitivity to sunlight have a tendency to develop sunburns and frequently lack the ability to acquire a tan following exposure to UV light. These individuals with diminished sun response tend to display cutaneous hyperpigmented spots such as nevi or ephelides more commonly than people who are able to tan easily $(13,14)$.

Skin sensitivity to sunlight, together with light skin (and light hair and eye colour) and incapacity to tan are all risk phenotypes conferring susceptibility to develop skin cancers - including basal cell carcinoma, squamous cell carcinoma and the more dangerous melanoma. In fact, several genes involved in skin pigmentation - such as $M C 1 R, I R F 4, S L C 45 A 2$, and so on - are known to behave as low-penetrance genes for melanoma and other skin cancers (15).

Most of the studies aimed at addressing the genetic determinants of skin photosensitivity and/or tanning ability have been performed in populations of North European origin, both in northern Europe and in North America (3-5,16-19). However, there is a shortage of studies carried out in darker-skinned populations such as southern 
Europe or the Mediterranean (20-25). These more southerly populations present lower percentages of highly sun-sensitive individuals and higher percentages of individuals that are capable of tanning with ease. Accordingly, allele frequencies of the variants responsible for pigmentation in southern Europe may differ from those further north (26). Due to higher UV radiation in South Europe, mainly during the summer months, evolution has probably influenced the distribution of allele frequencies of several human pigmentation genes in a different way to North Europe. For example, the F374 allele in SLC45A2, responsible for darker skin, is significantly more frequent in Spain than in more northerly European populations $(27,28)$.

In this study, we set out to elucidate the genetic determinants of sun photosensitivity in Spain, a population of Mediterranean origin, by means of testing variation in the genes previously associated with sun sensitivity. We have performed SNP genotyping in 8 pigmentation-related genes (HERC2, SLC45A2, SLC24A4, TYR, ASIP, OCA2, BNC2 and $I R F 4$ ) as well as complete gene sequencing of the $M C 1 R$ gene in 456 individuals of Spanish origin. The correlation of the genetic variants with skin photosensitivity, and the interaction among all the associated genes, are analysed.

\section{MATERIALS AND METHODS}

\section{Study subjects and data collection}

A total of 456 cancer-free volunteers (272 controls and 184 cases) were included in this case-control study. Individuals with low sensitivity to sunlight, who never or rarely burn and always tan after sun exposure (Fitzpatrick skin phototypes III-IV-V), were included in the control group. Conversely, individuals presenting high sensitivity to sunlight, who always or often burn and never or seldom tan after sun exposure (phototypes I-II), 
were defined as cases. All individuals were Europeans of Spanish origin. Written informed consent was provided by all participants, and the study was approved by the Ethics Committee of the Jaume I University of Castellon (Castellon, Spain).

A standardised questionnaire was used to collect information on sex, age, place of birth, place of residence during childhood, pigmentation traits (skin, hair and eye colour), freckling degree, history of childhood sunburns, skin sensitivity to sunlight (tanning ability versus tendency to burn), Fitzpatrick's skin type classification, and sun exposure habits. To avoid misclassification, all questionnaires were completed by a professional dermatologist.

\section{DNA isolation, SNP selection and genotyping assays}

Genomic DNA was isolated from saliva samples using QIAamp DNA Mini Kit (Qiagen, Hilden, Germany), according to the manufacturer's protocol.

We selected genes previously associated with skin sensitivity to sunlight and tanning ability $(4,5,16,18,19)$. Nine SNPs located in 8 pigmentation-related genes were finally genotyped: rs4911442 (located in the ASIP gene), rs2153271 (BNC2 gene), rs12913832 (HERC2 gene), rs1800407 (OCA2 gene), rs12896399 (SLC24A4 gene), rs16891982 (SLC45A2 gene), rs1393350 and rs1042602 (TYR gene), and rs12203592 (IRF4 gene).

Genotyping assays were performed by using KASP Genotyping Chemistry (LGC, Hoddesdon, United Kingdom) or TaqMan technology (Applied Biosystems, Foster City, USA). PCR conditions varied depending on the requirements of each probe, always according to the manufacturer's recommendations. For quality control, we 
included a negative control and a trio of samples with known genotype (major allele homozygous, heterozygous and minor allele homozygous) in each 96-well plate. Unsuccessful genotyping rate was lower than 5\% in all SNPs analysed.

The $M C 1 R$ gene was studied by direct genetic sequencing with the Sanger method, as previously described (29). A sample with known $M C 1 R$ genotype per 96-well plate was added for quality control. Sixteen samples $(3.49 \%)$ were discarded because of unsuccessful $M C 1 R$ sequencing.

\section{Statistical analysis}

Statistical analyses were performed using the R software (http://www.R-project.org). All analyses were two-sided, and a significance level of 0.05 was considered for rejection of the null-hypothesis. Correction for multiple hypothesis testing was carried out using the Bonferroni method $\left(P\right.$-value $\left.<4.54 \times 10^{-3}=0.05 / 11\right)$. Unknown and missing values were excluded at each specific analysis.

Descriptive statistics (means, standard deviations, sample size, percentages) were used to report demographic characteristics, sun sensitivity traits, and sun exposure habits of participants (Table 1). For categorical variables, Fisher's exact test was used to evaluate differences between cases and controls. Mann-Whitney $U$ test was used to account for differences in age between cases and controls, since age was not normally distributed according to the Shapiro-Wilk test. 
For genetic association analyses, non-synonymous $M C 1 R$ mutations were classified as previously described (25). Individuals were then classified according to the number of $\mathrm{R}$ and/or $\mathrm{r}$ alleles carrying. The individual effect of each $M C 1 R$ variant was evaluated.

Association between all variants studied and sunlight sensitivity was assessed according to the additive model of inheritance via logistic regression adjusted by sex, estimating odds ratios (ORs) per variant carried, their corresponding $95 \%$ confidence intervals (CIs) and associated $P$-values. All genetic analyses were performed estimating the effect of the minor allele in the Spanish population.

Fisher's exact test was used to study combinations of protective and risk genotypes in different genes for skin photosensitivity. Interactions among sunlight sensitivityassociated genes were tested using the multifactor dimensionality reduction (MDR) method (MDR software v.1.2) (30). The MDR method tests all potential locus-locus combinations to create a model that sorts cases and controls with the lowest possible classification error. That procedure is repeated 10 times in order to obtain both the cross-validation $(\mathrm{CV})$ consistency, the number of times that a particular model is chosen as the best one; and the balanced accuracy (BA), the proportion of occurrences correctly classified using the model. 


\section{RESULTS}

Evidence of association with skin sensitivity to sunlight for the genetic variants studied was assessed (Table 2). All associations observed were significant after Bonferroni correction. $\mathrm{R}$ variants of the $M C 1 R$ gene were the most strongly associated with sunlight sensitivity $\left(P\right.$-value $\left.=2.00 \times 10^{-6}\right)$, being the OR estimated per variant carried of 2.55. The rs 16891982 polymorphism in SLC45A2 presented the second strongest association with sunlight sensitivity $\left(P\right.$-value $\left.=6.79 \times 10^{-5}\right)$, observing a protective effect of the $\mathrm{G}$ minor allele regarding tolerance to sunlight $(\mathrm{OR}=0.57)$. Significant associations were also observed for HERC2 $\operatorname{rs} 12913832\left(P\right.$-value $\left.=9.35 \times 10^{-5}\right)$ and $I R F 4$ rs12203592 $\left(P\right.$-value $\left.=4.75 \times 10^{-4}\right)$. For these two polymorphisms, carrying a copy of the minor allele significantly increased the risk of being highly sensitive to sunlight $(\mathrm{OR}=$ 1.62 for rs 12913832, and OR $=1.98$ for rs12203592). No associations were found for the remaining genetic variants.

Moreover, interaction effects between SLC45A2 rs16891982 and the other genetic variants influencing sunlight sensitivity were assessed. A significantly increased percentage of $H E R C 2 \mathrm{rs} 12913832 * \mathrm{C}$ carriers $\left(P\right.$-value $\left.=9.97 \times 10^{-3}\right), I R F 4$ rs $12203592 * \mathrm{~T}$ carriers $\left(P\right.$-value $\left.=3.62 \times 10^{-3}\right)$ or $M C 1 R$ R carriers $\left(P\right.$-value $\left.=1.31 \times 10^{-3}\right)$ were detected in highly photosensitive individuals harbouring at least one copy of the rare protective allele in SLC45A2 rs16891982 (Figure 1). According to the MDR method, sunlight sensitivity was best explained assuming interaction between polymorphisms in all four sun sensitivity-associated genes $(\mathrm{BA}=0.679, \mathrm{CV}$ consistency $=10 / 10, P$-value $<0.0001)$. Significant redundant interaction was observed between MC1R R variants, IRF4 rs 12203592 and SLC45A2 rs16891982 (indicated by black lines in Figure 2). 


\section{DISCUSSION}

In the current study, nine pigmentation-related genes were examined in 456 individuals from Spain, with the intention of analysing their putative implication in skin sensitivity to sunlight - a phenotypic trait with substantial clinical importance for both melanoma and non-melanoma skin cancer.

As shown in previous studies performed in populations of North European ancestry $(4,5,16,31)$, our results confirm an association between sunlight sensitivity and genetic variants in the MC1R, SLC45A2, HERC2 and IRF4 genes in a Mediterranean population.

The $M C 1 R$ gene has been previously described as one of the major contributors to the diversity of human pigmentation (32). The melanocortin-1 receptor is a $\mathrm{G}$ proteincoupled receptor expressed on the melanocyte's membrane surface that is involved in the regulation of melanocyte proliferation and function (33). Stimulation of MC1R by melanocortins following sunlight exposure leads to the activation of photoprotective eumelanin biosynthesis, being essential to the tanning response and offering greater protection against skin cancer $(34,35)$. Among all non-synonymous $M C 1 R$ variants described (33), R variants have been the most frequently associated with fair skin, red hair, freckling and poor tanning ability $(36,37)$ - all phenotypes increasing the risk of developing skin cancer. As expected, in this study individuals carrying R variants in $M C 1 R$ present a significantly higher risk of sunburn after sunlight exposure, confirming the impact of $M C 1 R$ gene polymorphism on tanning ability and the risk of sunburn shown in previous population-based studies $(38,39)$. However, our findings show an 
absence of a significant effect of the $\mathrm{r}$ variants on sunlight sensitivity. These results are consistent with those reported by Latreille et al. (38), which found that $r$ variants were significantly associated with freckling (usually a signal of high sensitivity to sunlight) but not with sunburn event frequency nor suntan intensity.

The SLC45A2 gene, which encodes a membrane-associated transporter protein involved in arranging melanogenic enzymes during melanosome maturation, has been previously defined as a human pigmentation-related and melanoma-susceptibility gene. Genetic variants of the $S L C 45 A 2$ gene, located in both the promoter region and the coding region, have been significantly associated with dark pigmentation and with protection against melanoma in southern European populations (40-42). In this study, we focused on the rs16891982 polymorphism in SLC45A2, which results in a non-synonymous change (F374L). The percentage of the ancestral F374 allele among European individuals is only $6.2 \%$, conferring a protective effect against melanoma and other skin cancers in populations of European ancestry, while more than $96 \%$ of Africans harbour this protective allele (www.ensembl.org). In our Spanish dataset, the percentage of the ancestral allele was $9.0 \%$ in individuals with high sunlight sensitivity, while a considerable increase was observed in individuals with higher tanning ability and lower susceptibility to sunburns (16.2\%). This clearly indicates that the SLC45A2 rs $16891982 * \mathrm{C}$ minor European allele is evidently associated with a protective phenotype against skin cancer.

The HERC2 locus is also associated with human pigmentation variation, through the modification of the expression of $O C A 2$, a pigmentation gene contiguous to HERC2. Variation in rs12913832 has been identified as a genetic determinant for human blue- 
brown eye colour as well as hair colour $(31,43)$. In our study, the derived $\mathrm{C}$ allele is significantly associated with high sensitivity to sunlight, as in previous studies in populations of northern European origin (5).

IRF4 has also been associated with pigmentation characteristics in several studies $(4,44)$. This interferon regulatory factor cooperates with MITF to activate the expression of tyrosinase in melanocytes, a function that seems to be impaired in carriers of the rs $12203592 * \mathrm{~T}$ derived minor allele (45). From the results of our study, we can confirm that this gene is important in the skin sensitivity to sunlight in the Spanish population, since it is highly associated with this phenotype. The derived $\mathrm{T}$ allele has previously been associated with tanning ability (5), and melanoma susceptibility (21).

Since human pigmentation has been demonstrated to be a highly polygenic trait $(1,2,15)$, and epistasis has been suggested to play an important role in the determination of human pigmentation traits (46-48), we decided to perform a gene-gene interaction analysis in order to obtain clues on the possible epistatic effects influencing skin photosensitivity.

Regarding sensitivity to sunlight, and noticing that the frequency of the SLC45A2 ancestral protective allele in Spain (18.2\%, www.ensembl.org) is considerably higher than in other European populations (including Italian Tuscans at 3.3\%), we decided to extend our analyses to assess the interaction between protective (carriers of at least one ancestral SLC45A2 rs $16891982 *$ C allele) and risk genotypes in other sun sensitivityassociated genes. The MDR interaction analysis found that sunlight sensitivity is better explained by taking into account the effect of MC1R, IRF4, SLC45A2 and HERC2. As 
seen in Figure 1 and Table 3, risk alleles in MC1R, IRF4 and HERC2 are able to mitigate the protective effect of carrying at least one SLC45A2 rs16891982*C allele.

It is important to keep in mind that there is still considerable ambiguity in the definition of the term 'skin sensitivity to sunlight' or 'skin photosensitivity', being difficult to perform a comprehensive comparison with previous published studies. Data standardisation should be addressed in future investigations by employing consistent definitions in order to allow for meta-analysis studies. Another possible caveat is that this study may indeed be ignoring the effect of other unknown genetic variants on skin photosensitivity, since we only focused on pigmentation-related genes previously associated - though through several potent GWAS - with skin sensitivity to sunlight and tanning ability.

In short, this study shows that the $M C 1 R$ gene is the major contributor to skin photosensitivity in the Spanish population, specifically by way of its $R$ variants. Besides, genetic variants in SLC45A2, HERC2 and IRF4 are also significantly associated with sunlight sensitivity in individuals of Spanish origin, independently of sex. However, large-scale replication collecting phenotypic traits related to photosensitivity in different southern European populations is necessary to confirm our findings. 


\section{ACKNOWLEDGEMENTS}

We are extremely grateful to all volunteers for taking part in this study, as well as to all medical specialists for supervising phenotype collection of all samples.

This work was supported by Council of Education of the Generalitat Valenciana (Grant number GV/2016/156), and co-funded by Jaume I University of Castellon (Grant number UJI-A2016-13). BH is funded by the Jaume I University of Castellon under Research Contract No. 15721. 


\section{REFERENCES}

1 Liu F, Wen B, Kayser M. Colorful DNA polymorphisms in humans. Semin Cell Dev Biol 2013: 24: 562-575.

2 Sturm R A. Molecular genetics of human pigmentation diversity. Hum Mol Genet 2009: 18: R9-17.

3 Nan H, Kraft P, Hunter D J et al. Genetic variants in pigmentation genes, pigmentary phenotypes, and risk of skin cancer in Caucasians. Int J Cancer J Int Cancer 2009: 125: 909-917.

4 Sulem P, Gudbjartsson D F, Stacey S N et al. Genetic determinants of hair, eye and skin pigmentation in Europeans. Nat Genet 2007: 39: 1443-1452.

5 Nan H, Kraft P, Qureshi A A et al. Genome-wide association study of tanning phenotype in a population of European ancestry. J Invest Dermatol 2009: 129: $2250-2257$.

6 Khalesi M, Whiteman D C, Tran B et al. A meta-analysis of pigmentary characteristics, sun sensitivity, freckling and melanocytic nevi and risk of basal cell carcinoma of the skin. Cancer Epidemiol 2013: 37: 534-543.

7 Barón A E, Asdigian N L, Gonzalez V et al. Interactions between ultraviolet light and MC1R and OCA2 variants are determinants of childhood nevus and freckle phenotypes. Cancer Epidemiol Biomarkers Prev 2014: 23: 2829-2839.

8 Newton-Bishop J A, Chang Y-M, Iles M M et al. Melanocytic nevi, nevus genes, and melanoma risk in a large case-control study in the United Kingdom. Cancer Epidemiol Biomarkers Prev 2010: 19: 2043-2054.

9 Gallagher R P, Hill G B, Bajdik C D et al. Sunlight exposure, pigmentary factors, and risk of nonmelanocytic skin cancer. I. Basal cell carcinoma. Arch Dermatol 1995: 131: 157-163.

10 Gallagher R P, Hill G B, Bajdik C D et al. Sunlight exposure, pigmentation factors, and risk of nonmelanocytic skin cancer. II. Squamous cell carcinoma. Arch Dermatol 1995: 131: 164-169.

11 Gandini S, Sera F, Cattaruzza M S et al. Meta-analysis of risk factors for cutaneous melanoma: III. Family history, actinic damage and phenotypic factors. Eur J Cancer Oxf Engl 1990 2005: 41: 2040-2059.

12 D’Orazio J, Jarrett S, Amaro-Ortiz A et al. UV Radiation and the Skin. Int J Mol Sci 2013: 14: 12222-12248.

13 Dodd A T, Morelli J, Mokrohisky S T et al. Melanocytic nevi and sun exposure in a cohort of colorado children: anatomic distribution and site-specific sunburn. Cancer Epidemiol Biomarkers Prev 2007: 16: 2136-2143. 
14 Ezzedine K, Mauger E, Latreille J et al. Freckles and solar lentigines have different risk factors in Caucasian women. J Eur Acad Dermatol Venereol 2013: 27: e345356.

15 Scherer D, Kumar R. Genetics of pigmentation in skin cancer--a review. Mutat Res 2010: 705: 141-153.

16 Sulem P, Gudbjartsson D F, Stacey S N et al. Two newly identified genetic determinants of pigmentation in Europeans. Nat Genet 2008: 40: 835-837.

17 Jacobs L C, Hamer M A, Gunn D A et al. A Genome-Wide Association Study Identifies the Skin Color Genes IRF4, MC1R, ASIP, and BNC2 Influencing Facial Pigmented Spots. J Invest Dermatol 2015: 135: 1735-1742.

18 Eriksson N, Macpherson J M, Tung J Y et al. Web-based, participant-driven studies yield novel genetic associations for common traits. PLoS Genet 2010: 6: e1000993.

19 Gerstenblith M R, Shi J, Landi M T. Genome-wide association studies of pigmentation and skin cancer: a review and meta-analysis. Pigment Cell Melanoma Res 2010: 23: 587-606.

20 Ibarrola-Villava M, Hu H-H, Guedj M et al. MC1R, SLC45A2 and TYR genetic variants involved in melanoma susceptibility in southern European populations: results from a meta-analysis. Eur J Cancer Oxf Engl 1990 2012: 48: 2183-2191.

21 Peña-Chilet M, Blanquer-Maceiras M, Ibarrola-Villava $\mathrm{M}$ et al. Genetic variants in PARP1 (rs3219090) and IRF4 (rs12203592) genes associated with melanoma susceptibility in a Spanish population. BMC Cancer 2013: 13: 160.

22 Fernandez L P, Milne R L, Pita G et al. Pigmentation-related genes and their implication in malignant melanoma susceptibility. Exp Dermatol 2009: 18: 634642.

23 Hernando B, Peña-Chilet M, Ibarrola-Villava M et al. Genetic 3'UTR variation is associated with human pigmentation characteristics and sensitivity to sunlight. Exp Dermatol 2017: 26: 896-903.

24 Hernando B, Ibarrola-Villava M, Peña-Chilet M et al. Sex and MC1R variants in human pigmentation: Differences in tanning ability and sensitivity to sunlight between sexes. J Dermatol Sci 2016: 84: 346-348.

25 Hernando B, Ibañez M V, Deserio-Cuesta J A et al. Genetic determinants of freckle occurrence in the Spanish population: Towards ephelides prediction from human DNA samples. Forensic Sci Int Genet 2018: 33: 38-47.

26 Sturm R A, Duffy D L. Human pigmentation genes under environmental selection. Genome Biol 2012: 13: 248.

27 López S, García O, Yurrebaso I et al. The interplay between natural selection and susceptibility to melanoma on allele $374 \mathrm{~F}$ of SLC45A2 gene in a South European population. PloS One 2014: 9: e104367. 
28 Lucotte G, Mercier G, Diéterlen F et al. A decreasing gradient of 374F allele frequencies in the skin pigmentation gene SLC45A2, from the north of West Europe to North Africa. Biochem Genet 2010: 48: 26-33.

29 Ibarrola-Villava M, Fernandez L P, Pita G et al. Genetic analysis of three important genes in pigmentation and melanoma susceptibility: CDKN2A, MC1R and HERC2/OCA2. Exp Dermatol 2010: 19: 836-844.

30 Hahn L W, Ritchie M D, Moore J H. Multifactor dimensionality reduction software for detecting gene-gene and gene-environment interactions. Bioinforma Oxf Eng1 2003: 19: 376-382.

31 Han J, Kraft P, Nan H et al. A Genome-Wide Association Study Identifies Novel Alleles Associated with Hair Color and Skin Pigmentation. PLoS Genet 2008: 4: e1000074.

32 Sturm R A, Teasdale R D, Box N F. Human pigmentation genes: identification, structure and consequences of polymorphic variation. Gene 2001: 277: 49-62.

33 García-Borrón J C, Abdel-Malek Z, Jiménez-Cervantes C. MC1R, the cAMP pathway, and the response to solar UV: extending the horizon beyond pigmentation. Pigment Cell Melanoma Res 2014: 27: 699-720.

34 Sturm R A. Skin colour and skin cancer - MC1R, the genetic link. Melanoma Res 2002: 12: 405-416.

35 Abdel-Malek Z A, Swope V B, Starner R J et al. Melanocortins and the melanocortin 1 receptor, moving translationally towards melanoma prevention. Arch Biochem Biophys 2014: 563: 4-12.

36 Bastiaens M, Huurne J ter, Gruis $\mathrm{N}$ et al. The melanocortin-1-receptor gene is the major freckle gene. Hum Mol Genet 2001: 10: 1701-1708.

37 García-Borrón J C, Sánchez-Laorden B L, Jiménez-Cervantes C. Melanocortin-1 receptor structure and functional regulation. Pigment Cell Res 2005: 18: 393-410.

38 Latreille J, Ezzedine K, Elfakir A et al. MC1R gene polymorphism affects skin color and phenotypic features related to sun sensitivity in a population of French adult women. Photochem Photobiol 2009: 85: 1451-1458.

39 Sturm R A, Duffy D L, Box N F et al. The role of melanocortin-1 receptor polymorphism in skin cancer risk phenotypes. Pigment Cell Res 2003: 16: 266-272.

40 Fernandez L P, Milne R I, Pita G et al. SLC45A2: a novel malignant melanomaassociated gene. Hum Mutat 2008: 29: 1161-1167.

41 Ibarrola-Villava M, Fernandez L P, Alonso S et al. A Customized Pigmentation SNP Array Identifies a Novel SNP Associated with Melanoma Predisposition in the SLC45A2 Gene. PLoS ONE 2011: 6: e19271. 
42 Graf J, Voisey J, Hughes I et al. Promoter polymorphisms in the MATP (SLC45A2) gene are associated with normal human skin color variation. Hum Mutat 2007: 28: $710-717$.

43 Sturm R A, Duffy D L, Zhao Z Z et al. A single SNP in an evolutionary conserved region within intron 86 of the HERC2 gene determines human blue-brown eye color. Am J Hum Genet 2008: 82: 424-431.

44 Praetorius C, Sturm R A, Steingrimsson E. Sun-induced freckling: ephelides and solar lentigines. Pigment Cell Melanoma Res 2014: 27: 339-350.

45 Praetorius C, Grill C, Stacey S N et al. A polymorphism in IRF4 affects human pigmentation through a tyrosinase-dependent MITF/TFAP2A pathway. Cell 2013: 155.

46 Branicki W, Brudnik U, Wojas-Pelc A. Interactions between HERC2, OCA2 and MC1R may influence human pigmentation phenotype. Ann Hum Genet 2009: 73: $160-170$.

47 Pastorino L, Cusano R, Bruno W et al. Novel MC1R variants in Ligurian melanoma patients and controls. Hum Mutat 2004: 24: 103.

48 Akey J M, Wang H, Xiong M et al. Interaction between the melanocortin-1 receptor and $\mathrm{P}$ genes contributes to inter-individual variation in skin pigmentation phenotypes in a Tibetan population. Hum Genet 2001: 108: 516-520. 


\begin{tabular}{|c|c|c|c|c|c|c|}
\hline \multirow[b]{2}{*}{ Gene } & \multirow[b]{2}{*}{ SNP \# rs } & \multirow[b]{2}{*}{ Genotype } & \multirow{2}{*}{$\frac{\text { Low photosensitivity }}{\mathrm{N}(\%)}$} & \multicolumn{3}{|c|}{ High photosensitivity } \\
\hline & & & & N (\%) & OR $(95 \%$ CI) & $P$-value ${ }^{1}$ \\
\hline \multirow[t]{3}{*}{$A S I P$} & rs4911442 & AA & $234(86.35)$ & $151(82.07)$ & $1.30(0.82-2.08)$ & 0.268 \\
\hline & & $\mathrm{AG}$ & $34(12.55)$ & $31(16.85)$ & & \\
\hline & & GG & $3(1.11)$ & $2(1.09)$ & & \\
\hline \multirow[t]{3}{*}{$B N C 2$} & rs2153271 & TT & $69(25.37)$ & $59(32.07)$ & $0.86(0.64-1.14)$ & 0.292 \\
\hline & & $\mathrm{CT}$ & $154(56.62)$ & $96(52.17)$ & & \\
\hline & & $\mathrm{CC}$ & $49(18.01)$ & $29(15.76)$ & & \\
\hline \multirow[t]{3}{*}{$H E R C 2$} & rs 12913832 & TT & $101(37.97)$ & $46(25.70)$ & $1.62(1.23-2.13)$ & 4.75E-04* \\
\hline & & $\mathrm{CT}$ & $123(46.24)$ & $80(44.69)$ & & \\
\hline & & $\mathrm{CC}$ & $42(15.79)$ & $53(29.61)$ & & \\
\hline \multirow[t]{3}{*}{ IRF4 } & rs 12203592 & $\mathrm{CC}$ & $203(74.40)$ & $104(56.83)$ & $1.98(1.40-2.81)$ & 9.35E-05* \\
\hline & & $\mathrm{CT}$ & $64(23.53)$ & $67(36.61)$ & & \\
\hline & & TT & $5(1.80)$ & $12(6.56)$ & & \\
\hline \multirow[t]{3}{*}{$O C A 2$} & rs 1800407 & $\mathrm{CC}$ & $226(84.01)$ & $143(79.89)$ & $1.26(0.81-1.97)$ & 0.302 \\
\hline & & $\mathrm{CT}$ & $40(14.87)$ & $33(18.44)$ & & \\
\hline & & $\mathrm{TT}$ & $3(1.12)$ & $3(1.68)$ & & \\
\hline \multirow[t]{3}{*}{$S L C 24 A 4$} & rs 12896399 & GG & $86(31.97)$ & $54(29.67)$ & $0.94(0.73-1.22)$ & 0.655 \\
\hline & & GT & $120(44.61)$ & $76(41.76)$ & & \\
\hline & & $\mathrm{TT}$ & $63(23.42)$ & $52(28.57)$ & & \\
\hline \multirow[t]{3}{*}{$S L C 45 A 2$} & rs 16891982 & GG & $200(73.53)$ & $160(87.43)$ & $0.57(0.39-0.83)$ & $6.79 \mathrm{E}-05 *$ \\
\hline & & $\mathrm{CG}$ & $56(20.59)$ & $13(7.10)$ & & \\
\hline & & $\mathrm{CC}$ & $16(5.88)$ & $10(5.46)$ & & \\
\hline \multirow[t]{3}{*}{$T Y R$} & rs 1393350 & GG & $157(57.72)$ & $99(54.10)$ & $1.11(0.82-1.51)$ & 0.485 \\
\hline & & $\mathrm{AG}$ & $98(36.03)$ & $72(39.34)$ & & \\
\hline & & AA & $17(6.25)$ & $12(6.56)$ & & \\
\hline \multirow[t]{3}{*}{$T Y R$} & rs 1042602 & $\mathrm{CC}$ & 87 (31.99) & $47(25.54)$ & $1.19(0.91-1.56)$ & 0.207 \\
\hline & & $\mathrm{AC}$ & $134(49.26)$ & $99(53.80)$ & & \\
\hline & & AA & $51(18.75)$ & $38(20.65)$ & & \\
\hline \multirow[t]{3}{*}{$M C 1 R$} & $\mathrm{R}$ alleles & $0 / 0$ & $214(81.06)$ & 109 (61.93) & $2.55(1.73-3.75)$ & 2.00E-06* \\
\hline & & $0 / R$ & 48 (18.18) & $55(31.25)$ & & \\
\hline & & $\mathrm{R} / \mathrm{R}$ & $2(0.76)$ & $12(6.82)$ & & \\
\hline \multirow[t]{3}{*}{$M C 1 R$} & $\mathrm{r}$ alleles & $0 / 0$ & $151(57.20)$ & $94(53.41)$ & $1.05(0.77-1.43)$ & 0.755 \\
\hline & & $0 / \mathrm{r}$ & $94(35.61)$ & $69(39.20)$ & & \\
\hline & & $\mathrm{r} / \mathrm{r}$ & $19(7.20)$ & $13(7.39)$ & & \\
\hline
\end{tabular}

SNP, single nucleotide polymorphism; MAF, minor allele frequency; OR, odds ratio per allele copy; CI, confidence interval; N, number of individuals; \%, percentage of individuals per group among the total

Individuals with low skin sensitivity to sunlight were set as reference group for association analysis. Association analysis were adjusted by sex. Bold indicates statistically significant results. * Indicates significant results at Bonferroni threshold of 4.54E-03

${ }^{1} P$-values were calculated via logistic regression according to the additive model of inheritance. The minor allele effect was estimated. For $M C 1 R$, the effect of $\mathrm{R}$ and $\mathrm{r}$ alleles was estimated. 
Table 3. Interactions between variants and their effect in skin photosensitivity

\begin{tabular}{|c|c|c|c|c|c|c|}
\hline \multirow[b]{2}{*}{ rs16891982 (SLC45A2) } & \multirow[b]{2}{*}{ rs12913832 (HERC2) } & \multicolumn{3}{|c|}{ Individuals (N) } & \multirow[b]{2}{*}{ OR (95\% Cl) } & \multirow[b]{2}{*}{$P$-value ${ }^{a}$} \\
\hline & & $\begin{array}{c}\text { Low } \\
\text { photosensitivity }\end{array}$ & $\begin{array}{c}\text { High } \\
\text { photosensitivity }\end{array}$ & Total & & \\
\hline \multirow[t]{2}{*}{ G/G } & $\mathrm{T} / \mathrm{T}$ & 69 & 42 & 111 & 1.00 & reference \\
\hline & $\mathrm{C} /-$ & 124 & 116 & 240 & $1.52(1.13-2.07)$ & $6.34 \mathrm{E}-03$ \\
\hline \multirow[t]{2}{*}{ C/- } & $\mathrm{T} / \mathrm{T}$ & 31 & 4 & 35 & $0.22(0.06-0.81)$ & 0.022 \\
\hline & $\mathrm{C} /-$ & 41 & 17 & 58 & $2.50(1.26-4.96)$ & 9.97E-03 \\
\hline rs16891982 (SLC45A2) & rs12203592 (IRF4) & & $\mathbf{N}$ & & & \\
\hline \multirow[t]{2}{*}{ G/G } & $\mathrm{C} / \mathrm{C}$ & 147 & 94 & 241 & 1.00 & reference \\
\hline & $\mathrm{T} /-$ & 53 & 65 & 118 & $1.86(1.27-2.73)$ & $1.42 \mathrm{E}-03$ \\
\hline \multirow[t]{2}{*}{ C/- } & $\mathrm{C} / \mathrm{C}$ & 55 & 10 & 65 & $0.41(0.23-0.74)$ & 3.09E-03 \\
\hline & $\mathrm{T} /-$ & 17 & 13 & 30 & $3.60(1.52-8.53)$ & $3.62 \mathrm{E}-03$ \\
\hline rs16891982 (SLC45A2) & $\mathrm{R}$ alleles $(M C 1 R)$ & & & & & \\
\hline \multirow[t]{2}{*}{ G/G } & $0 / 0$ & 158 & 99 & 257 & 1.00 & reference \\
\hline & $\mathrm{R} /-$ & 36 & 55 & 91 & $2.32(1.52-3.55)$ & $9.70 \mathrm{E}-05$ \\
\hline \multirow[t]{2}{*}{ C/- } & $0 / 0$ & 55 & 9 & 64 & $0.39(0.22-0.71)$ & $1.92 \mathrm{E}-03$ \\
\hline & $\mathrm{R} /-$ & 14 & 12 & 26 & $5.22(1.91-14.33)$ & $1.31 \mathrm{E}-03$ \\
\hline \multicolumn{7}{|c|}{ OR, odds ratio per allele copy; $\mathrm{Cl}$, confidence interval; $\mathrm{N}$, number of individuals } \\
\hline \multicolumn{7}{|c|}{${ }^{a} P$-values were calculated via logistic regression. Significant results are presented in bold. } \\
\hline \multicolumn{7}{|c|}{ * Indicates significant results at Bonferroni threshold of $4.54 \mathrm{E}-03$} \\
\hline
\end{tabular}




\section{FIGURE LEGENDS}

Figure 1. Plot showing the percentage of $S L C 45 A 2$ protective $\operatorname{rs} 16891982 * \mathrm{C}$ carriers with low and high sensitivity to sunlight according to $H E R C 2, I R F 4$ and $M C 1 R$ genotype. $P$-value was calculated for the Fisher's exact test.

\section{Figure 2. Dendrograms showing gene-gene interactions that influence skin} photosensitivity modelled by using the MDR software. Black lines represent a high degree of redundancy (negative information gain), with a lesser degree represented by grey lines. 
Plot showing the percentage of SLC45A2 protective rs $16891982 * \mathrm{C}$ carriers with low and high sensitivity to sunlight according to HERC2, IRF4 and MC1R genotype. P-value was calculated for the Fisher's exact test. 
Dendrograms showing gene-gene interactions that influence skin photosensitivity modelled by using the MDR software. Black lines represent a high degree of redundancy (negative information gain), with a lesser degree represented by grey lines. 